This is a manuscript of an article subsequently published as:

Walz, M., Hoyer, P. and Statler, M. (2016). After Herzog: Blurring fact and fiction in visual organizational ethnography. Journal of Organizational Ethnography, 5(3): 202-218.

The published version can be accessed here: http://dx.doi.org/10.1108/JOE-07-2016-0017 @Emerald

\title{
After Herzog: Blurring fact and fiction in visual organizational ethnography
}

\author{
Markus Walz \\ Stockholm Business School, Stockholm University, Sweden \\ Patrizia Hoyer \\ Research Institute for Organizational Psychology, University of St. Gallen, Switzerland \\ Matt Statler \\ NYU Stern School of Business, New York University, USA
}

\begin{abstract}
Purpose - The purpose of this paper is to introduce the unique artistic approach of filmmaker Werner Herzog as an inspiration to rethink ethnographic studies in general and the notion of reflexivity in particular.

Approach - This paper reviews the particularities of Werner Herzog's approach to film making, linking them to the methodological tradition of visual ethnography and especially the debate about the role of reflexivity and performativity in research.

Findings - Herzog's conceptualization of meaning as 'ecstatic truth' offers an avenue for visual organizational ethnographers to rethink reflexivity and performativity, reframe research findings and reorganize research activities. The combination of multiple media and the strong authorial involvement exhibited in Herzog's work, can inspire and guide the development of 'meaningful' organizational ethnographies.

Originality/value - The paper argues that practicing visual organizational ethnography 'after Herzog' offers researchers an avenue to engage creatively with their research in novel and highly reflexive ways. It offers a different way to think through some of the challenges often associated with ethnographic research.
\end{abstract}

Keywords Visual Organizational Ethnography, Reflexivity, Performativity, Werner Herzog Paper type Conceptual paper 


\section{Introduction}

Organization theory is shaped not only metaphorically (Morgan, 1996), but also materially, by its images. Put differently: the collective social practice of organization theory constitutes itself, becomes what it is, in and through a series of processual entanglements with a variety of material dimensions, including the physical environment, the institutional context, discursive regularities, etc., and images. It has been acknowledged that organizational researchers have only recently begun to pay serious attention to visuality more broadly (Bell \& Davison, 2013; Bell et al., 2013; Meyer et al., 2013). Still, there is an emerging consensus among visual organizational scholars that the practice of organizational theory has always been materially shaped and constrained not only by the images that it constructs of organizations, leaders, managers, workers, contracts, and so on, but also of itself as a discipline, a social practice that achieves legitimacy at least in part by creating knowledge that has relevance for organizational practice.

Thus it is interesting from an auto-ethnographic perspective to consider those images we organizational theorists create and have of ourselves. Based on personal reflections and conversations with colleagues, we suggest that many of these images remain fleeting, rarely investigated, and thus almost invisible. But not only does the field of organizational theory lack rich and nuanced images of itself, we lack images because we have not dedicated ourselves to the creation of them. Meyer et al. (2013) acknowledge that, "[o]nly a few researchers in our field have harnessed the advantages of systematically documenting and analyzing their research in a visual way so far (p. 516)." Perhaps the most dramatic exceptions are Lines of Flight (Wood \& Brown, 2010) and Leadership in Spaces and Places (Salovaara, 2014). Both of these works are documentary films that depict the researcher, the research process and the novel understandings that organizational research can create. Both of these works can be understood as highly reflexive as well as performative, and both explicitly address material dimensions of organizational research including the materiality of images themselves. We find these works inspiring and we would like to see many more similar projects. Toward that end, the motivation for this paper is to expand the realm of what is considered possible or appropriate for organizational researchers and visual ethnographers to do.

The rhetorical conceit will be to construct an image of Werner Herzog as a visual organizational ethnographer. More specifically, we view Herzog's work within the tradition of organizational ethnography that utilizes visual 
methods and emphasizes aspects of reflexivity and performativity. We focus specifically on Herzog's (1999) notion of "ecstatic truth", which he claims provides an alternative to "accountant truth", and we consider the significance of this distinction with regard to debates within organizational theory about the epistemological status of visuality and materiality. We highlight how Herzog's practice of combining different artistic media can be a source of potential inspiration for organizational researchers who seek to open new paths for reflexivity by conducting multimodal research. But before presenting an account of Herzog's artistic practices, we review the organizational literature on visual ethnography, focusing specifically on reflexivity and performativity.

\section{Performing reflexivity}

\section{Reflexivity as central to ethnographic research}

Following Weick (1999), management researchers must engage reflexively with themselves by thinking about their own reasoning. The notion of reflexivity has the effect of contesting the image of an "all-knowing, all-seeing, objective and omnipotent (Hardy \& Clegg, 1997, p. 5)" researcher, yet as Johnson and Duberley (2003) note, the term reflexivity is used rather broadly. Some scholars use it to express a holistic, complex and synthetic

understanding (see e.g. Bleakley, 1999), while others have sharply criticized a trend towards "hyperreflexivity" (Sass, 1994), framing it as a cultural obsession with self-reflection and self-absorption which cultivates detached introspective consciousness rather than an interest in the everyday of social phenomena (Bleakley, 1999; Hillmann, 1989). Thus although we acknowledge that reflexive engagement risks producing mere "confessional tales" (Van Maanen, 1988), we follow Denzin's (2001) call for “an interpretive social science that is simultaneously autoethnographic, vulnerable, performative and critical (p. 43)."

Reflexivity may be a critical characteristic of interesting research texts in general (Alvesson \& Sandberg, 2013), but it is particularly crucial to ethnographic work, given the intimate role of the researcher in the ethnographic context. And if we follow Louis" (1991) argument that “I am an instrument of my inquiry: and the inquiry is inseparable from who I am (p. 365 cited in Humphreys, 2005, p. 842)," then ethnography appears to require a commitment to remain reflexive to a degree that is higher than in other modes of qualitative research (see also Hammersley \& Atkinson, 2007). As Tedlock (1991) claimed regarding participant observation methods, 
ethnographic research practices need to give voice and reflect upon the role of the other and the role of the self simultaneously.

Ethnography is one of the methodologies in the social sciences that explicitly and deliberately presents a particular (researcher's) point of view, since it is not possible to describe the world from 'God's perspective' (Cardano, 2009; Putnam, 1981). Moreover, a reflexive description allows the scientific community to engage in a sort of thought experiment for following the ethnographer in his or her itinerary and for scrutinizing the empirical conditions under which certain research outputs were formulated (Cardano, 2009). Reflexivity should however not be mistaken for a methodological algorithm, but instead it can be seen as a call for creativity and imagination in ethnographic work, like introducing arts-based methods (Taylor \& Ladkin, 2009).

Not only but also because of its potential to foster reflexivity, there is renewed excitement about ethnography in the field of organization and management studies (see Ybema et al., 2009). Rouleau et al. (2014) even speak of an "ethnographic turn" driven by a new generation of organizational ethnographers. While taking note of the early roots of ethnographic work on organizational bureaucracies in the 1950s, as well as its rise in the late 1970 s, the current resurgence of interest in organizational ethnography is often attributed to a number of favorable conditions including the complex, fragmented and dispersed nature of organizational life which calls for (more) context-sensitive methods and the advancement of social media and other technologies. New ethnographic genres have emerged (Rouleau et al., 2014), including multi-sited ethnography (Marcus, 1998), self-ethnography (Ellis, 2004), network ethnography (Howard, 2002), critical ethnography (Madison, 2005) and visual ethnography (Pink, 2007). Here, we draw particularly on this tradition of visual ethnography in order to begin constructing our image of Werner Herzog as an organizational researcher.

\section{Reflexive imagery through visual ethnography}

Pink (2013) defines visual ethnography as a research approach that involves (audio-) visual media methods and it is mostly considered as a collaborative effort between the researcher and research participants. While pioneered by anthropologist John Collier in the 1960s when he formalized how photography can be used methodologically (see Collier \& Collier, 1986), during the 1990's new innovations in visual technologies as well as critical postmodern 
conceptions of experience and representation paved the way towards even greater degrees of acceptance for visual methodologies. In the past decade then, with the growing importance of "non-representational" (see e.g. Thrift, 2007) and "more-than- representational" (Lorimer, 2005) theories in human geography and anthropology, practices of visual ethnography became part of a broader move towards different forms of visual scholarship (Pink, 2013). Not surprisingly then, visual methods have been used and argued for within the social sciences. Paula Reavey and others (see Reavey, 2012) have discussed how images can be used meaningfully within psychology research. Similarly, Douglas Harper (2012) summarized his thoughts on the importance of visual methods for sociology. Others like for example Gillian Rose (2016) or Sarah Pink (2013) have moreover discussed the role of visual methods within the fields of geography and anthropology respectively, and even beyond their disciplines. And yet, even if visual methodologies have been addressed and applied in various different research fields, Steyaert et al. (2012) argue that organization studies rely most dominantly still on the study of words, thereby often failing to capture the multiplicity which can be encountered in processes of organizing. And yet, growing research attention to visual practices and methodologies (Bell \& Davison, 2013; Bell et al., 2013; Meyer et al., 2013) underlines an increasing sensitivity to the aesthetic qualities of organizational life. Organizational scholars are picking up on the idea that visual methods give ethnographers the unprecedented opportunity to capture, access and analyze the minutiae of fast-paced organizational practices, while potentially making their research outputs more amenable for non-academic audiences (see Smets et al., 2014). And still, utilizing such methods remains somewhat exotic in most business schools.

One crucial point of discussion is the distinction between realist and critical ethnography. In a realist view visual methods can help to re-create an observable reality by providing narrations as close to the actual experience as possible. In contrast to that, from a critical view ethnography as a whole is seen as one avenue of linking individual experiences to a critique of social structure. With regards to ethnographic filmmaking, it should be noted that these practices are historically often placed in the realist attempt to depict social life through documentaries that minimize the influence of the film-maker, letting the material guide the film and avoiding the use of a narrator (Hassard, 2009; Steyaert et al., 2012), often called 'cinéma vérité.' Following a critical approach, the centrality of both the researcher and the study participants in knowledge production is reflected upon and thought to ideally achieve an emancipatory effect. Here ethnographic documentaries may go beyond the mere description of 'the 
world as it is' and instead help to enact a particular version of reality (Beyes \& Steyaert, 2013; Hassard \& Buchanan, 2009; Law, 2004; Steyaert et al., 2012). Within this performative view (Berger \& Luckman, 1967, cited by Meyer et al., 2013, p. 491), visual practices may be situated and framed as being part of a reflexive methodology (Pink, 2001), a methodology that makes visible the multiple, intricate and contradictory nature of one's own research practices, thereby mirroring and potentially (re)producing the complexity of the phenomena that are being studied (Denzin, 1997; Steyaert et al., 2012). Embracing this viewpoint, Mannay (2016, p. 68) describes visual research as a powerful way to "fight familiarity, engender participatory practice and provide the basis for reflexive qualitative inquiry."

The work of Vietnamese filmmaker, writer and professor Trinh T. Minh-ha, provides one illustrative example of how ethnographic documentaries can break with the realist tradition of filmmaking and instead introduce a genre of hybridization between academic practices of theorizing and artistic approaches of visual experimentation. Steyaert et al. (2012; see also Denzin, 2001) particularly highlight her film Surname Viet Given Name Nam (Bourdier \& Trinh, 1989). The film shows how Vietnamese women change their names or not depending on whether they marry a foreigner or a Vietnamese. The film has multiple layers, also staging some interviews which were interestingly "acted" by Vietnamese women who at the end of the film were interviewed about their experience of playing these roles. The film is a powerful illustration of how the 'real' and the 'staged' intermingle, as the audience does not know that these are actresses re-enacting the actual interviews (conducted by Mai Thu Van) or that the interviews were conducted in the United States and not in Vietnam, which is only revealed near the end of the film (Denzin, 2001). By publishing scripts of her projects (see Trinh, 1992, 1999) or by offering theoretical treatises of her movies, Trinh has turned traditional academic writing into a genre of more evocative and rich prose (Steyaert et al., 2012). In her work, reflexivity is performed and the outcome provides a clear precedent for the hybridization of aesthetic and academic work. Richardson (2015) gives another example of how to creatively handle the performative nature of research encounters. Using his verbatim interview transcripts as the basis for a theater play script, the experiences of his interview participants are staged and played back to them (and their environment) in order to create a more meaningful impact of his biographical research on Irish men in diaspora, not least for the participants of his study. This project allows for the identity struggles of these men to become part of a greater narrative within their community and offers a creative way of bringing the interview transcripts back into the 
foreground. Acknowledging such precedent, we turn now to another potential resource for creative visual approaches and reflexive practice, namely the work of Werner Herzog.

\section{Werner Herzog's artistic practices}

Why have we chosen to focus on Werner Herzog in particular? As will hopefully become clear in the remainder of the paper, we believe that Herzog can be an inspiration for researchers who are interested in working with the medium of film. We find him to be a filmmaker who manages to explore topics in comprehensive ways, while at the same time telling meaningful stories, even if the topics of his films might sound obscure to some at first (like for example ski flying, or living with wild grizzlies). We argue that Herzog helps to capture one aspect of polyphonic research as described by Bates (1997), namely through his blurring of boundaries between what is considered real and what is considered fake. Most importantly Herzog challenges us to move beyond the confinements of a single piece of research output and to rethink our own work as Gesamtkunstwerk in order to enable a more reflexive engagement with our research. When discussing his work we have chosen to highlight particular movies, some of them because we feel that the theme of the movie is very close to topics that critical organizational researchers might want to explore. For example, we read his movie Into the Abyss (Stipetic \& Herzog, 2011) as a case study of the social context of murder and capital punishment in the US, and we have picked other movies because some parts of them highlight a crucial aspect of Herzog's unique approach. When analyzing the movies, we do not focus on the technical level of how and by whom the visuals were created, but instead we try to highlight 'for what purpose'.

\section{Herzog as reflexive practitioner}

The German-born Werner Herzog is one of the most renowned contemporary independent filmmakers. Throughout his career he has directed over 50 films, written several books, staged theater productions (especially operas), and acted in various movies made by other directors. Herzog has been showered with praise and is somewhat of a cult figure in the art house scene. But from early on, Herzog has also been a controversial figure. Some have looked with skepticism for instance at Herzog's ways of self-portrayal (see Wahl, 2002), others have 
accused him of mistreating the native population of the Peruvian Amazon during film projects (see for example Davis \& Jenkins, 1985). Herzog refutes these allegations in his diary, Conquest of the Useless, as fabricated and illspirited, yet the air of controversy remains.

Herzog often recounts the moment when he realized he wanted to be a film-maker as an epiphany. Having grown up in a small Bavarian village just after the Second World War, Herzog had his first contact with the medium of film when a travelling projectionist visited his village. He remembers that when watching a movie, he realized that the same shot was used twice, which for him triggered his first critical engagement with film as a medium. He recounts:

Before this moment I thought it was some kind of reality I had been watching on screen, that the film was something like a documentary. All of a sudden I could see how the film was being narrated and edited, how tension and suspense were created, and from that day on cinema was something different for me (Cronin, 2002, p. 9).

The reason we have chosen Herzog in particular as an inspiration and potential role model for how to conduct visual organizational ethnography is that from the very beginning, his own film work exhibits a reflexive attitude towards filmmaking as art and skepticism towards what has been described as the "myth of transparency (Bell \& Davison, 2013, p. 174)," the idea that images and film are capturing true and authentic moments. Herzog embraces instead a performative view of his art, seeing the task of the film-maker as one of crafting or composing a new set of meaningful images. What distinguishes Herzog from other filmmakers or visual scholars, and what has drawn our attention to his work in particular, is that Herzog pushes the envelope. In contrast to Minh-ha for example, Herzog does not necessarily acknowledge what parts of his movie have been staged within the context of the same artwork. Instead, he challenges the interested viewer/reader to go beyond the single movie to learn about the directorial/authorial decisions and practices, and to consider reflexively whether the art has any meaning.

Even further, Herzog denies that there is a meaningful boundary between feature films and documentaries. Instead, he draws a distinction between "accountant truth" and "ecstatic truth" (Herzog, 1999). Accountant truth, as he sees it, is the type of truth that most scholars, journalists, and documentary film-makers seek, a superficial truth preoccupied with facts where its seekers "resemble tourists who take pictures amid ancient ruins of facts (1999)." For him "to convey 'facts' in his films - as do for example, ethnographic documentaries - would be the same as looking at a poem by Hölderlin about a storm in the alps and proclaiming 'Ah, here we have a weather 
report back in 1802'” (Cronin, 2002, p. 252 in Prager, 2007, p. 6). Instead, Herzog explains that his concept of 'truth' is grounded in the notion of art rather than an image of 'the world out there'. To push his point even further, Herzog goes as far as to claim that documentaries are no truer than fiction, given that both genres present things which are manipulated and staged alongside things which are not (directly) staged. Consequently, for Herzog an "aesthetic lie" can be "truer than the truth" (Prager, 2007, p. 8).

Similar to Bate's (1997) description of the tenets of ethnographic work, the author is always a performer undermining the distinction between fiction and non-fiction. Even in his more documentarist work, he blurs genre boundaries, blends fictional and non-fictional elements, often disregarding conventional rules regarding transparency towards the audience. His movies have therefore been described as U.F.O.s (Unidentified Filmic Objects) (Vitiello, 2012, p. 550), in which Herzog tries to express an ecstatic truth that enables poetic and mysterious experience attained through fabrication and stylization and as Singer (2012) notes: "Herzog's métier here is proof of Rancière's claim that 'The real must be fictionalized in order to be thought'” (p. 576). But aestheticization does not necessarily corrupt the value of ethnographic work. For Bate, fabrication or fictionalization can help to fulfill what he regards as one crucial element of good ethnographies, namely polyphony and rich description (the others are: creating a sense of being there, capturing the mundane and having a punchline). We will later come back on how exactly we see polyphony in Herzog's work when describing his multimodality, but for now we can say that in Herzog's work polyphony is not achieved by minimizing authorial presence and letting the participants/actors talk for themselves, but by juxtaposing 'real' and fictitious events (see also Bate, 1997).

\section{Following Herzog into the abyss?}

To give some examples of how Herzog tries to attain such ecstatic truth in his work, we first turn to his production Little Dieter Needs to Fly (Stipetić \& Herzog, 1997), a film about Vietnam War veteran Dieter Dengler and his experience as a prisoner of war. In this film Herzog stages interview scenes with the real Dengler, who reenacts different experiences from his ordeal in the Vietnamese jungle, including armed guards played by locals. This leads to a rather surreal moment when Dieter sitting next to a local actor standing in as a guard retells the torture and 
pain he experienced when being chained up every night. The scene ends with Dengler laying his arm around the actor, saying: 'Don't worry, it's just a movie', so that the actual prisoner of war reminds us, the viewers, as well that we are watching a fictionalization of his ordeal even though it appears to us as a documentary on the surface. We learn from Peucker (2012) that Herzog had actually scripted and rehearsed many scenes with Dengler, like for example a scene showing the protagonist compulsively checking the locks in his house (as a sign of some kind of post-traumatic response to his years of imprisonment), although the real Dengler had no such compulsion.

A more recent example is Herzog's documentary film Into the Abyss. The film can be described as a case study of the aftermath of a murder case in which Sandra Stotler, the victim, was murdered when she caught two young men trying to steal her car. In Montgomery County, Texas, Herzog interviews the two convicted murderers, their family members, friends of both the murderers and the victims, as well as law enforcement officers including people involved in the execution of one of the murderers who was sentenced to death (and executed shortly after his interview with Herzog). The film encourages the viewer to reflect upon the social conditions that lead to such crimes as well as the legitimacy of the use of capital punishment by the state to deter people from committing them. In other words, we find that Herzog presents a convincing argument for the importance of understanding the social conditions of murder; he presents a creative ethnography of a murder case. In this regard, Into the Abyss appears a fascinating example of how organizational ethnographers can have a strong authorial presence and still voice polyphony, providing a stimulus to reflect upon the complexities of crime, murder and capital punishment. Herzog insists that film has a unique capacity to enable reflection:

Film has such a strange quality; it allows us to look deep into the heart of humanity. It has a strange quality of illuminating something that's deep inside of us. And I'm not only speaking of documentaries, it's the same procedure with feature films. So...why it is like that, I don't know. I can only say yes, it allows us to look into the abyss (Herzog \& Smith, 2014).

Just short of the abyss, we suggest that film can help to facilitate the intimacy, detail orientation, narrativity and sensuousness that organizational ethnographers seek (Vannini, 2014). On the other hand, the abyss metaphor can also stand in for the ethical challenges posed by such visual approaches in general, and Herzog's practices in particular. A classic example is the iconic photograph Migrant Mother, picturing poverty in the Great Depression era. The woman pictured never gave consent and the photographer did not bother to get the details of the pictured mother's backstory right, nonetheless the picture was praised as the ultimate expression of the plight 
many people had to go through at that time (see also Mannay, 2016). Given our fascination with Herzog and our own argument for transferring his art into art based research practice, we have to acknowledge some of the same ethical challenges as well. Brady and Brown (2013, p. 102) reflecting on their research project on teenage pregnancy state that their art-based approach "raises a number of important questions for us, associated with both the process and the legacy of the projects, in relation to issues of anonymity, confidentiality and informed consent and the role of the researcher in the production of knowledge." Similar to their reflections, in the case of Herzog's movie one starts to wonder about what responsibility he the director/auteur has towards the participants. Does Herzog provide an eye-opening view into the social context of murder or does he through his editorial decisions provide us with a now immortalized picture of specific groups in society till 'time immemorial'? Mannay (2016) asks a similar question when she describes the problem that visual materials, like photographs will develop a life of their own and will often be interpreted in a decontextualized way. Regarding the Migrant Mother photography, she points out how the picture was often taken as a glorification of white (American) motherhood against unfortunate circumstances, while the actual ethnic background (Cherokee) of the mother was lost. While decontextualized interpretation is not necessarily a sole problem of visual methods, it accentuates the need to think carefully about appropriate distribution channels for this type of research in order to minimize a decontextualized consumption of the material.

In other words, we acknowledge that a Herzogian approach will confront the same difficult challenges faced by visual methods in general, like giving participants authorship and voice (see Lomax, 2015), or the meaning of 'informed consent' within such creative, visual based approaches (see Renold et al., 2008). Yet a further ethical challenge posed by transferring Herzog into research practice is related to the distinction between what it means to be an artist and what role a social scientist has to play. As we consider yet another crucial aspect of Herzog's work, the potential challenge his approach poses to what many would consider standard scientific practice will become clearer.

Take Herzog's statement regarding the opening in his Gulf War film Lessons of Darkness (Stipetić \& Herzog, 1992). This controversial Iraq war science fiction (as he likes to call it) opens with the following quote attributed to $17^{\text {th }}$ century mathematician and philosopher Blaise Pascal: "the collapse of the stellar universe will occur - like 
creation - in grandiose splendor." Yet when confronted with the fact that the source of this quote could not be verified, Herzog (in Herzog \& Weigel, 2010) answered as follows:

The words attributed to Blaise Pascal which preface my film Lessons of Darkness are in fact by me. Pascal himself could not have said it better. This falsified and yet, as I will later demonstrate, not falsified quotation should serve as a first hint of what I am trying to deal with in this discourse. Anyway, to acknowledge a fake as fake contributes only to the triumph of accountants. Why am I doing this, you might ask? The reason is simple and comes not from theoretical, but rather from practical, considerations. With this quotation as a prefix I elevate [erheben] the spectator, before he has even seen the first frame, to a high level, from which to enter the film. And I, the author of the film, do not let him descend from this height until it is over. Only in this state of sublimity [Erhabenheit] does something deeper become possible, a kind of truth that is the enemy of the merely factual. Ecstatic truth, I call it (p. 1).

Here we can observe a crucial difference between Herzog and Trinh T. Minh-ha's approach discussed earlier. Whereas Trinh is transparent about the fictional elements within the context of a single art work, as she reveals the fakery and addresses it within the context of the same movie (see Surname Viet Given Name Nam), Herzog is not. Herzog does not claim any kind of scientific authority, so he can invoke the freedom of artistic expression to absolve himself of any failure to provide accurately representational 'accountant's truth'. Moreover, though Herzog resolutely refuses to articulate the meaning of his work using words, he clearly believes that his work provokes viewers to create meaning for themselves. So while Herzog's techniques seem to contradict the traditional spirit of documentary film-making, his approach appears to echo the notion that in interpretative organizational research "the truth of the story lies not in its accuracy but its meaning (Gabriel, 1998, p. 136 in Humphreys, 2005, p. 855)."

In his approach, he seems "perversely academic" (Kael, 1975), but maybe such perversion is just what is needed in order to help us, as organization theorists, move towards a clearer understanding of the visuality of our own practices (see Meyer et al., 2013). Still, many of us will recognize the challenge such perversity will post on the distinction between the artist and the researcher/social scientist. Are we as social scientists not restricted by a greater responsibility towards protecting our study participants? And do we not have a greater need to be transparent with our audience? We argue that considering one more crucial aspect of Herzog's approach helps to quiet such worries at least a bit. 


\section{Organizational theory as Gesamtkunstwerk: Multimodality after Herzog}

His efforts to create ecstatic truth include the performative embrace of a wide variety of different media or genres of communication. Herzog has for instance published diaries from his movie shoots in the Amazonian jungle (Herzog, 2009), has filmed a cinematic self-portrait (Stipetic \& Herzog, 1986), collaborated with a friend and colleague in shooting documentaries of himself and his projects (Blank \& Blank, 1980; 1982), and has reflected on his infamous collaboration with actor Klaus Kinski who starred in five of Herzog's films and in a documentary piece (Stipetić \& Herzog, 1999). Herzog himself has starred in satirical programs poking fun at his own trademark characteristics such as in Incident at Loch Ness and The Grand (Penn \& Penn, 2004, 2007), or in The Simpsons (Kimball, Maxtone-Graham \& Schoefield, 2011), and used the stereotype of himself as the dark, melancholic, hermit European film-maker by playing the villain in one of Tom Cruise's action movies, Jack Reacher (Cruise \& McQuarrie, 2012). There is also no shortage of interview material where Herzog argues his case and shares his take on his projects and his view of film as art (see for example Ames, 2014, for a recent interview collection).

Combining several media outlets is a technique Herzog shares with Trinh mentioned earlier. But in Herzog's case it is essential to look at his oeuvre in its totality. His 'truth performances', if not to say 'fakeries', are not revealed within the individual work, but instead one needs to look beyond, at his other movies, his writings, his performances to appreciate them. In fulfillment of Bate's (1997) ideal, not only are Herzog's ethnographies polyphonic, but Herzog himself, as the ethnographer, is polyphonic. Driven by his quest for ecstatic truth, Herzog returns to similar questions over and over again. Some have argued that his new films at times seem to be made "in the service of re-enacting and thereby revisiting his own cinematic past (Ames, 2012, p. 410)." To some extent Herzog's work can be considered as a Gesamtkunstwerk, as one broad attempt to create ecstatic truth.

For organizational ethnographers, Herzog provides a source of inspiration if not a model worthy of imitation. Echoing Vannini's (2014) claim that scholars need to become more open to alternative ways of conducting research, embracing visual methods, and remembering Bate's (1997) critique that way too often the commitment to ethnography on organizational scholarship is mere lip service, we think that Werner Herzog can show us one way to create greater understanding of organizational life. As we hopefully have made clear, Herzog does not only 
offer inspiration on how to produce aesthetically pleasing documentary films, but his approach can also stimulate us theoretically and encourage us to become more reflexive researchers.

\section{Herzog and the practice of visual organizational ethnography}

The relevance of Herzog's work for visual organizational ethnography can be further established by analyzing one of his films in reference to a typology developed by Meyer et al. (2013) of different approaches to the status of visuals in research design. These approaches include: archeological, practice, strategic, dialogical and documenting. Herzog's work - indeed, each individual film - exemplifies aspects of all of these distinct traditions, not by employing one rigorous methodological approach (as his intent is not to produce a piece of formulaic research), but in that his work offers opportunity to express crucial aspects inherent in the individual approaches. For example, in Cave of Forgotten Dreams (Nelson \& Herzog, 2010) Herzog works directly with the archeological relevance of visuals. This film is composed primarily of unprecedented footage shot inside the Chauvet cave in southern France which contains the oldest known human paintings, and secondarily of interviews with archaeologists, art historians and social theorists. Herzog tries to explore the culture that created these images for example by reflecting upon the fact that the paintings show nearly no human figures. With the help of the featured scientists, he speculates on the social meaning behind these artifacts and works as an archeologist exploring an ancient visual culture.

In this way, these same archeological phenomena also have practical relevance as "socially meaningful material objects that are created, employed, and manipulated in organizational contexts (Meyer et al., 2013, p. 503)," and not only in the historical case of Neolithic culture but also in reference to our own contemporary culture. By looking at the way visual artifacts were handled in prehistoric caves, we see by contrast the ways in which visual artifacts are handled in contemporary organizational life. Herzog is similarly clear that the cave paintings, no less than his own film about them, "are symbolic devices that exert influence and impact on audiences; perception and evaluation of reality (Meyer et al., 2013, p. 503)." In another segment of Cave of Forgotten Dreams, an expert talking head suggests that the Neolithic painters saw the boundary between themselves and animals as porous - in other words, their own existence was intertwined with the existence of animals to an extent that they could become animals in a ritualized context, and return then from animal form to 
human form. The world of humanity was not, it is suggested, fully distinct from the world of animals, and so the painters saw no need to depict anthropomorphic figures, focusing almost exclusively on bears, deer, horses, rhinos, etc. Herzog would deflect questions about whether it was his intention to produce this effect in viewers, but one ecstatic truth presented by the film is precisely this blurring of the distinction between the human and non-human.

With regard to the strategic aspect mentioned by Meyer et al., seeing Herzog and the film participants struggling to give meaning to the paintings and how they are then being presented to us, we are offered an opportunity to see how visuals are means of persuasion. We can observe how the author(s) develop(s) an interpretation (in the voice-over) and then stages this interpretation (with the visuals he/they present). Using film as his preferred method, Herzog offers the study participants - in this case the scientists exploring the cave - an opportunity to have a greater impact than in a written account. In this sense, his work is dialogical as it gives some control back to the participants in creating visuals. Herzog co-creates visuals "that speak to deeper elements of human consciousness and, thus, elicit richer information (Meyer et al., 2013, p. 503)," and as a film-maker, he affirms the notion that visuals are "well-suited [as] means of documentation and presentation of ... perspective." Finally, the fact that Herzog inserts himself into the movie is a way of realizing the documenting potential of visual organizational ethnography. He is able to showcase his perspective in an embodied way through visualizing it. For example, when discussing the cave paintings one expert notes that the earliest paintings from 35,000 years ago were retouched by later artists as many as 10-15,000 years later who nevertheless painted in the same style with the same media. In a voiceover, Herzog raises questions about how difficult it is to imagine, in our media-saturated and rapidly-changing visual environment, that a single style would survive over so many millennia. What would our culture be like, he inquires, if our own visual methods were so static in time? Here Herzog acts as the interpreter and tries to give meaning to the paintings in the context of our visual culture.

Thus, although Herzog does not aspire to work in a rigorously defined methodological tradition, the example of Cave of Forgotten Dreams illustrates how Herzog can act as an inspiration for visual ethnographers. In the final section of this paper we turn to consider the implications that this inspiration may have for organizational studies more generally. 


\section{Implications beyond visual organizational ethnography}

In this paper we have discussed the work of filmmaker Werner Herzog as a model for visual ethnographic research that embraces reflexivity in the context of organization and management studies and challenges our own understanding of the role of the researcher versus the role of the author. Having entertained this rhetorical conceit at length, we believe that Herzog's work fits well into a research orientation that subscribes to the understanding that ethnography is not a matter of representing a reality which is 'out there' and which can be captured through truthful documentaries. On the contrary, Herzog challenges the distinction between things that are real and things that are staged, constructed or even faked. Beyond what others have suggested, Herzog - in his search for (aesthetic) meaning rather than facts - goes as far as blurring the distinction between documentary and fiction.

We have argued that Herzog's radicalism, his willingness to provoke and his obligations to the arts position him as a model for how to pursue original ethnographic research and creative arts-based approaches within organization studies. We have focused in particular on his practices of stimulating audiences to engage in reflections; utilizing different artistic media to presenting research findings in unconventional ways; and treating his various engagements as Gesamtkunstwerk. More practically, Herzog's work challenges us to embrace visual research creatively and to challenge traditional forms of authorship by inviting novel forms of interaction between the researcher, the research object, the audience, as well as the material world. Along those lines, Beyes and Steyaert (2011) reflect more broadly upon the interface between research and the arts, arguing that the integration of art into organizational research is emblematic of a broader aesthetic turn in the social sciences (see also Thrift, 2007) which signifies a renewed interest in the artist as ethnographer (see also Johnstone, 2008) or vice versa.

Most importantly, Herzog's practice can help us to live up to the various calls for being more reflexive. Alvesson, Hardy and Harley (2008) identify four textual practices available to organization scholars in order to write reflexively: multi-perspective, multi-voicing, positioning and destabilizing. While intended to be used mainly as a categorization of written practice, they can be transferred to research outputs in general and here we argue that Herzog offers one promising path to enact those practices. Others have attempted to enact reflexivity by re-visiting their own research with another theoretical lens, critically discussing their own research practice (e.g. Hardy, 
Phillips \& Clegg, 2001). Commonly these attempts end up in yet another journal article publication, whereas artsbased methods 'after Herzog' have the potential to make reflexivity into more than another written exercise and central in our research practice. By offering more layers to one's work, for example the visual, and by transgressing genre boundaries beyond the standard academic journal article format, we can treat our research practices more like a Gesamtkunstwerk. In our view this could be a more productive in creating reflexive scholarship that overcomes the challenge often encountered when trying to write reflexively within the framework of just one article. Like Cunliffe (2003, p. 990) summarizes: “Critics of reflexivity argue it has little to offer. Questioning what is real, what is knowledge, and who (or what) is self, leads only to intellectual chaos, self-indulgent [...] - all of which supposedly undermine serious research and make it impossible to say anything meaningful about theory or practice." A Herzogian approach would allow for a single output, like a journal article, to become more interesting by having a diary written during the writing process published, an ethnography written by a colleague or collaborator, the accumulation of commentary, in interviews, etc. Through such a process, a different and more reflexive image of organizational studies might emerge.

The invocation of Herzog as an image for social scientific practice can appear as naïve or idealistic at best. Should everyone try to create movies, publish their research diaries and so forth? Most organizational researchers will probably not possess the skills required to produce materials in all of these media or genres. In addition, given the current institutional forces shaping the field of organization studies, one has to wonder if anyone should. There are limited outlets for scholars to share their often amateurish attempts, and considering the immense publication pressure of contemporary business departments it might be wise, especially for young scholars, to stick to traditional journal publications. Still, if we dare to take the call for reflexive research practices and for arts-based approaches seriously, then Herzog's 'perversely academic' approach is one way of creating novel qualitative research practices. Whether we make movies or write articles or both, after Herzog we can engage in more playful and even more ecstatic modes of understanding organizational life. 


\section{Note}

Portions of this paper were presented at the 2014 Colloquium of the European Group for Organizational Studies in Rotterdam and the 2015 Academy of Management Annual Meeting in Orlando, FL.

\section{References}

Alvesson, M., Hardy, C., \& Harley, B. (2008), "Reflecting on reflexivity: Reflexive textual practices in organization and management theory", Journal of Management Studies, 45(3), pp. 480-501.

Alvesson, M. and Sandberg, J. (2013), Constructing Research Questions: Doing Interesting Research, Sage, Thousand Oaks, CA.

Ames, E. (2012), "The Case of Herzog: Re-Opened”, in Prager, B. (Ed.), A Companion to Werner Herzog, WileyBlackwell, Oxford, UK, pp. 393-415.

Ames, E. (Ed.) (2014), Werner Herzog: Interviews (conversations with filmmakers series), Mississippi University Press, Jackson, MS.

Atkinson, P. and Silverman, D. (1997), "Kundera's immortality: The interview society and the invention of the self", Qualitative Inquiry, Vol. 3, No. 3, pp. 304-325.

Bate, S.P. (1997), "Whatever happened to organizational anthropology? A review of the field of organizational ethnography and anthropological studies", Human Relations, Vol. 50, No. 9, pp. 1147-1175.

Bell, E., and Davison, J. (2013), "Visual management studies: Empirical and theoretical approaches", International Journal of Management Reviews, Vol. 15, No. 2, pp. 167-184.

Bell, E., Warren, S. and Schroeder, J.E. (2013), "The Visual Organization (Draft, January 31, 2013)", in Bell, E., Warren, S. and Schroeder, J.E. (Eds.), Routledge Companion to Visual Organization, Routledge, London, pp. $1-16$.

Berger, P.L. and Luckmann, T. (1967), The Social Construction of Reality, Anchor, Garden City, NY.

Beyes, T. and Steyaert, C. (2011), "The ontological politics of artistic interventions: Implications for performing action research", Action Research, Vol. 9, No. 1, pp. 100-115. 
Beyes, T. and Steyaert, C. (2013), "Strangely familiar: The uncanny and unsiting organizational analysis", Organization Studies, Vol. 34, No. 10, pp. 1445-1465.

Blank, L. (Producer) and Blank, L. (Director) (1980), Werner Herzog Eats His Shoe [Motion Picture], Flower Films, Los Angeles, CA.

Blank, L. (Producer) and Blank, L. (Director) (1982), Burden of Dreams [Motion Picture], Flower Films, Los Angeles, CA.

Bleakley, A. (1999), "From reflective practice to holistic reflexivity”, Studies in Higher Education, Vol. 24, No. 3, pp. 315-330.

Bourdier, J.-P. (Producer) and Trinh, T.M.-h. (Director) (1989), Surname Viet Given Name Nam [Motion Picture], Women Make Movies, New York, NY.

Brady, G., \& Brown, G. (2013), "Rewarding but let's talk about the challenges: Using arts based methods in research with young mothers", Methodological innovations online, 8(1), pp. 99-112.

Cardano, M. (2009), Ethnography and Reflexivity: Notes on the Construction of Objectivity in Ethnographic Research, Torino: Dipartimento di Scienze Sociali Università degli studi di Torino.

Collier, J., \& Collier, M. (1986). Visual anthropology: Photography as a research method. UNM Press, Albuquerque, NM.

Cronin, P. (2002), Herzog on Herzog, Farber and Farber, New York, NY.

Cruise, T. (Producer) and McQuarrie, C. (Director) (2012), Jack Reacher [Motion Picture], Paramount Pictures, Los Angeles, CA.

Cunliffe, A. L. (2003), "Reflexive inquiry in organizational research: Questions and possibilities", Human Relations, 56(8), pp. 983-1003.

Davis, H. and Jenkins, D. (1985), "Fitzcarraldo: Exotic and perverse", Jump Cut: A Review of Contemporary Media, 30(March1985).

Denzin, N.K. (1997), Interpretive Ethnography: Ethnographic Practices for the 21st Century, Sage, Thousand Oaks, CA.

Denzin, N.K. (2001), "The reflexive interview and a performative social science”, Qualitative Research, Vol. 1, No. 1, pp. 23-46. 
Ellis, C. (2004), The Ethnographic I: A Methodological Novel about Autoethnography. Alta Mira Press, Walnut Creek,

CA.

Gabriel, Y. (1998), "The use of stories", in Symon, G. and Cassell, C. (Eds.), Qualitative Methods and Analysis in Organizational Research: A practical guide, Sage, London, UK, pp. 135-160.

Hammersley, M. and Atkinson, P. (2007), Ethnography: Principles in Practice, Routledge, New York, NY.

Hardy, C. and Clegg, S. (1997), "Relativity without relativism: Reflexivity in post-paradigm organization studies", British Journal of Management, Vol. 8, No. s1, pp. 5-17.

Hardy, C., Phillips, N., \& Clegg, S. (2001), "Reflexivity in Organization and Management Theory: A Study of the Production of the Research Subject" Human Relations, 54(5), pp. 531-560.

Harper, D. (2012), Visual sociology. Routledge, New York, NY.

Hassard, J.S. (2009), "Researching work and institutions through ethnographic documentaries", in Buchanan D.A. and Bryman A. (Eds.), The SAGE Handbook of Organizational Research Methods, Sage, London, UK, pp. $270-281$.

Hassard, J.S. and Buchanan, D.A. (2009), "From Modern Times to Syriana: Feature films as research data", in D. A. Buchanan, D.A. \& Bryman, A. (Eds.), The SAGE Handbook of Organizational Research Methods, Sage, London, UK, pp. 620-635.

Herzog, W. (1999), “Minnesota Declaration”, available at http://www.wernerherzog.com/52.html (accessed 24 February, 2016).

Herzog, W. (2009), Conquest of Useless. Ecco Press, New York, NY.

Herzog, W. and Smith, M. (2014), “Into the Abyss: A conversation with filmmaker Werner Herzog” [Interview], available at http://www.flickeringmyth.com/2012/03/into-abyss-conversation-with-filmmaker.html (accessed 24 February, 2016).

Herzog, W. and Weigel, M. (2010), “On the absolute, the sublime, and ecstatic truth”, Arion, Vol. 17, No. 3, pp. 112.

Hillmann, J. (1989), “From mirror to window: Curing psychoanalysis of its narcissism”, Spring: A Journal of Archetype and Culture, Vol. 49, pp. 62-75. 
Howard, P.E.N. (2002), “Network ethnography and the hypermedia organization: New organizations, New Media, New Methods", New Media \& Society, Vol. 4, No. 4, pp. 551-575.

Humphreys, M. (2005), “Getting personal: Reflexivity and autoethnographic vignettes”, Qualitative Inquiry, Vol. 11, No. 6, pp. $840-860$.

Johnson, P. and Duberley, J. (2003), "Reflexivity in management research", Journal of Management Studies, Vol. 40, No. 5, pp. 1279-1303.

Johnstone, S. (Ed.) (2008), The Everyday, Whitechapel and MIT Press, Cambridge, MA.

Kael, P. (1975), “Metaphysical Tarzan (review of Kaspar Hauser)”, The New Yorker, 20 October, pp. 142-149.

Kimball, B., Maxtone-Graham, I. (Writers) and Schoefield, M. (Director). (2011), “A scorpion's tale” [Television series episode], in Groening, M. (Executive Producer), The Simpsons, $20^{\text {th }}$ Century Fox Television, Los Angeles.

Knorr Cetina, K. (1999), Epistemic Cultures: How the Sciences Make Knowledge, Harvard University Press, Cambridge, MA.

Law, J. (2004), After Method: Mess in Social Science Research, Routledge, New York, NY.

Lomax, H. (2015), "Seen and heard? Ethics and agency in participatory visual research with children, young people and families", Families, Relationships and Societies, 4(3), pp. 493-502.

Lorimer, H. (2005), “Cultural geography: The busyness of being 'more-than-representational'”, Progress in Human Geography, Vol. 29, No. 1, pp. 83-94.

Louis, M.R. (1991), "Reflections on an interpretive way of life”, in Frost, P.J., Moore, L.F., Louis, M.R., Lundberg, C.C. and Martin, J. (Eds.), Reframing Organizational Culture, Sage, London, UK, pp. 361-365.

Lynch, M. (2000), “Against reflexivity as an academic virtue and source of privileged knowledge”, Theory, Culture \& Society, Vol. 17, No. 3, pp. 26-54.

Madison, S. (2005), Critical Ethnography: Methods, Ethics and Performance, Sage, Thousand Oaks, CA.

Mannay, D. (2016), "Making the visual invisible: exploring creative forms of dissemination that respect anonymity but retain impact", Visual Methodologies, 3(2), pp. 67-76.

Marcus, G.E. (1998), Ethnography through Thick and Thin, Princeton University Press, Princeton, NJ. 
Meyer, R.E., Höllerer, M.A., Jancsary, D. and Van Leeuwen, T. (2013), "The visual dimension in organizing, organization, and organization research: Core ideas, current developments, and promising avenues", The Academy of Management Annals, Vol. 7, No. 1, pp. 489-555.

Morgan, G. (1996), “An afterword: Is there anything more to be said about metaphor”, in Grant, D. and Oswick, C. (Eds.), Metaphors and Organizations, Sage, Thousand Oaks, CA, pp. 227-240.

Nelson, E. (Producer) and Herzog, W. (Director) (2010), Cave of Forgotten Dreams [Motion Picture], IFC Films, USA.

Penn, Z. (Producer) and Penn, Z. (Director) (2004), Incident at Loch Ness [Motion Picture], 20 ${ }^{\text {th }}$ Century Fox, New York, NY.

Penn, Z. (Producer) and Penn, Z. (Director) (2007), The Grand [Motion Picture], Anchor Bay Entertainment, Beverly Hills, CA.

Peucker, B. (2012), “Herzog and auteurism: Performing authenticity”, in Prager, B. (Ed.), A Companion to Werner Herzog, Wiley-Blackwell, Hoboken, NJ, pp. 35-57.

Pink, S. (2001), "More visualising, more methodologies: on video, reflexivity and qualitative research", The Sociological Review, Vol. 49, No. 4, pp. 586-599.

Pink, S. (2007), Doing Visual Ethnography (2 ${ }^{\text {nd }}$ Edition), Sage, London, UK.

Pink, S. (2013), Doing Visual Ethnography (3 ${ }^{\text {rd }}$ Edition), Sage, London, UK.

Prager, B. (2007), The Cinema of Werner Herzog: Aesthetic Ecstasy and Truth, Wallflower Press, London, UK.

Putnam H. (1981), Reason, Truth and History, Cambridge University Press, Cambridge, UK.

Reavey, P. (Ed.) (2012), Visual methods in psychology: Using and interpreting images in qualitative research. Routledge: New York, NY.

Renold, E., Holland, S., Ross, N. J., \& Hillman, A. (2008), “Becoming Participant Problematizing 'Informed Consent' in Participatory Research with Young People in Care", Qualitative Social Work, 7(4), pp. 427-447.

Richardson, M. J. (2015), "Theatre as safe space? Performing intergenerational narratives with men of Irish descent", Social \& Cultural Geography, 16(6), pp. 615-633.

Rouleau, L., de Rond, M. and Musca, G. (2014), “From the ethnographic turn to new forms of organizational ethnography", Journal of Organizational Ethnography, Vol. 3, No. 1, pp. 2-9. 
Rose, G. (2016). Visual methodologies: An introduction to researching with visual materials. Sage, Thousand Oaks, CA.

Salovaara, P. (2014), “Video: Leadership in spaces and places”, Organizational Aesthetics, Vol. 3, No. 1, pp. 79-79.

Sass, L.A. (1994), Madness and Modernism: Insanity in the Light of Modern Art, Literature, and Thought, Harvard University Press, Cambridge, MA.

Singer, A. (2012), "Herzog and human destiny: The philosophical purposiveness of the filmmaker" in Prager, B.

(Ed.), A Companion to Werner Herzog, Wiley-Blackwell, Hoboken, NJ, pp. 566-586.

Smets, M., Burke, G., Jarzabkowsk, P. and Spee, P. (2014), “Charting new territory for organizational ethnography: Insights from a team-based video ethnography", Journal of Organizational Ethnography, Vol. 3, No. 1, 1026.

Steyaert, C., Marti, L. and Michels, C. (2012), "Multiplicity and reflexivity in organizational research: Towards a performative approach to the visual", Qualitative Research in Organizations and Management: An International Journal, Vol. 7, No. 1, pp. 34-53.

Stipetić, L. (Producer) and Herzog, W. (Director) (1986), Werner Herzog Filmemacher [Motion Picture], Werner Herzog Filmproduktion, München.

Stipetić, L. (Producer) and Herzog, W. (Director) (1992), Lessons of Darkness [Motion Picture], Werner Herzog Filmproduktion, München.

Stipetić, L. (Producer) and Herzog, W. (Director) (1997), Little Dieter needs to fly [Motion Picture], Werner Herzog Filmproduktion, München.

Stipetić, L. (Producer) and Herzog, W. (Director) (1999), My best Feind [Motion Picture], Zephir Films, London.

Stipetić, L. (Producer) and Herzog, W. (Director) (2011), Into the Abyss: A Tale of Death, a Tale of Life [Motion Picture], IFC Films, New York, NY.

Taylor, S.S. and Ladkin, D. (2009), "Understanding arts-based methods in managerial development", Academy of Management Learning \& Education, Vol. 8, No. 1, pp. 55-69.

Tedlock, B. (1991), “From participant observation to the observation of participation: The emergence of narrative ethnography", Journal of Anthropological Research, Vol. 47, No. 1, pp. 69-94.

Thrift, N. (2007), Non-representational Theory: Space, Politics, Affect, Routledge, London, UK. 
Trinh, T.M.-h. (1992), Framer Framed. Routledge, New York, NY.

Trinh, T.M.-h. (1999), Cinema Interval. Routledge, New York, NY.

Van Maanen, J. (1988), Tales of the Field: On Writing Ethnography, University of Chicago Press, Chicago, IL.

Vannini, P. (2014), “Ethnographic film and video on hybrid television learning from the content, style, and distribution of popular ethnographic documentaries", Journal of Contemporary Ethnography, Vol 44, No. 4, pp. 391-416.

Vitiello, G. (2012), "Portrait of the chimpanzee as a metaphysician: Parody and dehumanization in echoes from a somber empire", in Prager, B. (Ed.), A Companion to Werner Herzog. Wiley-Blackwell, Hoboken, NJ, pp. 547-565.

Wahl, C. (2012), "'I don't like the Germans': even Herzog started in Bavaria”, in Prager, B. (Ed.), A Companion to Werner Herzog, Wiley-Blackwell, Hoboken, NJ, pp. 547-565.

Weick, K.E. (1999), “Theory construction as disciplined reflexivity: Tradeoffs in the 90s", Academy of Management Review, Vol. 24, No. 4, pp. 797-806.

Wood, M. and Brown, S. (2011), “Lines of flight: Everyday resistance along England's backbone”, Organization, Vol. 18, No. 4, pp. 517-539.

Ybema, S., Yanow, D., Wels, H. and Kamsteeg, F. (2009), "Studying everyday organizational life”, in Ybema, S., Yanow, D., Wels, H. and Kamsteeg, F. (Eds.) Organizational Ethnography: Studying the Complexity of Everyday Life, Sage, London, UK, pp. 1-20.

\section{Further reading}

Atkinson, P. and Silverman, D. (1997), "Kundera's immortality: the interview society and the invention of the self", Qualitative Inquiry, Vol. 3 No. 3, pp. 304-325.

Knorr Cetina, K. (1999), Epistemic Cultures: How the Sciences Make Knowledge, Harvard University Press, Cambridge, MA.

Lynch, M. (2000), “Against reflexivity as an academic virtue and source of privileged knowledge”, Theory, Culture \& Society, Vol. 17 No. 3, pp. 26-54. 


\section{About the authors}

Markus Walz is a Doctoral Student at the Stockholm Business School, Stockholm University and a Visiting Scholar at the Business and Society Program Area at NYU Stern School of Business, New York University. His research project explores professional socialization within organizations, with a particular focus on the legal profession. Markus has presented his work at the European Group of Organization Studies Conference and the Academy of Management Annual Meeting and has published in ephemera. Markus Walz is the corresponding author and can be contacted at: markus.walz@sbs.su.se

Patrizia Hoyer is a Postdoctoral Researcher at the Research Institute for Organizational Psychology, University of St Gallen, Switzerland and a Visiting Fellow at the Lund University, Sweden. Her research interests include discursive and narrative approaches to identity, reflexive research methods, global career mobility and career change. Patrizia's work has been published in journals such as the British Journal of Management and Human Relations.

Matt Statler is the Richman Family Director of Business Ethics and Social Impact Programming, and a Clinical Associate Professor of Business and Society at the NYU Stern School of Business. Previously he served NYU's Center for Catastrophe Preparedness and Response as the Director of Research, and as an Associate Director of the International Center for Enterprise Preparedness. He also worked as the Director of Research and as a Research Fellow at the Imagination Lab Foundation in Lausanne, Switzerland, following several years as a Management Consultant in New York City. His latest research has appeared in the Journal of Business Ethics and the Journal of Management Education. 